\title{
Biomaterials
}

Biomaterials $21(2000)$ 1103-1114

\section{The effects of calcium phosphate cement particles on osteoblast functions}

\author{
Dominique P. Piolettia ${ }^{\mathrm{a}}$, Hiroshi Takei ${ }^{\mathrm{b}}$, Tong $\operatorname{Lin}^{\mathrm{a}}$, Pascale Van Landuyt ${ }^{\mathrm{c}}$, Quing Jun $\mathrm{Ma}^{\mathrm{a}}$, \\ Soon Yong Kwon ${ }^{\mathrm{b}}$, K.-L. Paul Sung ${ }^{\mathrm{a}, \mathrm{b}, \mathrm{d}, *}$ \\ ${ }^{a}$ Department of Bioengineering, University of California, San Diego, 9500 Gilman Drive, La Jolla, CA 92093-0412, USA \\ ${ }^{\mathrm{b}}$ Department of Orthopaedics, University of California, San Diego, 9500 Gilman Drive, La Jolla, CA 92093-0412, USA \\ ${ }^{\mathrm{c}}$ Department of Materials Science, Swiss Federal Institute of Technology, 1015 Lausanne, Switzerland \\ ${ }^{\mathrm{d}}$ Whitaker Institute of Biomedical Engineering, University of California, San Diego, 9500 Gilman Drive, La Jolla, CA 92093-0412, USA
}

Received 21 April 1999; accepted 5 November 1999

\begin{abstract}
Calcium phosphate cements (CPC) are increasingly used in the orthopedic field. This kind of cement has potential applications in bone defect replacements, osteosynthetic screw reinforcements or drug delivery. In vivo studies have demonstrated a good osteointegration of CPC. However, it was also observed that the resorption of CPC could create particles. It is known from orthopedic implant studies that particles can be responsible for the peri-implant osteolysis. Biocompatibility assessment of CPC should then be performed with particles. In this study, we quantified the functions of osteoblasts in the presence of $\beta$-TCP, brushite and cement particles. Two particle sizes were prepared. The first one corresponded to the critical diameter range 1-10 $\mu \mathrm{m}$ and the second one had a diameter larger than $10 \mu \mathrm{m}$. We found that CPC particles could adversely affect the osteoblast functions. A decrease in viability, proliferation and production of extracellular matrix was measured. A dose effect was also observed. A ratio of 50 CPC particles per osteoblast could be considered as the maximum number of particles supported by an osteoblast. The smaller particles had stronger negative effects on osteoblast functions than the larger ones. Future CPC development should minimize the generation of particles smaller than $10 \mu \mathrm{m}$. (C) 2000 Elsevier Science Ltd. All rights reserved.
\end{abstract}

Keywords: Osteoblast functions; Calcium phosphate cement particles

\section{Introduction}

Several calcium phosphate cements (CPC) have been developed and have potential use in orthopedic field [1-3]. Of these different CPC, the type of precipitation furnishes a classification of the cement type: brushite, hydroxyapatite, calcium-deficient hydroxyapatite, or amorphous calcium phosphate [4].

Calcium phosphate cements precipitating brushite have been developed by Lemaitre et al. for more than $10 \mathrm{yr}[5,6]$. $\beta$-Tricalcium phosphate $(\beta$-TCP) and monocalcium phosphate monohydrate powders are mixed with water and dissolution-precipitation phenomenon

\footnotetext{
* Correspondence address: Departments of Orthopaedics and Bioengineering, University of California, San Diego, 9500 Gilman Drive, La Jolla, CA 92093-0412, USA. Tel.: +1-619-534-5252; fax: +1-619534-6896.

E-mail address: klpsung@bioeng.ucsd.edu (K.-L. Paul Sung).
}

induces the formation of brushite, a dicalcium phosphate dihydrate (DCPD). Usually, these cements are prepared with an excess of $\beta$-TCP so that the ultimate cement is a mixture of brushite and residual $\beta$-TCP. More recently, small quantities of hydrosoluble polymers have been added to the mixing liquid for cement viscosity and injectability control [7]. The injectable CPC have several potential applications such as bone defect replacements [1], osteosynthetic screw reinforcements [8] and drug delivery [9].

To assess CPC biocompatibility, in vitro studies using the cement in a bulk form $[10,11]$ or in a very large particle size form [12] have been performed with different cell types. CPC were well tolerated by the bone cells and could enhance the production of different bone proteins. In vivo experiments on rabbits demonstrated that brushite was resorbed and replaced by newly formed bone within 3 months [2]. During CPC resorption, particle debris were noted around the periphery of the cement [13]. Intracellular accumulations of brushite 
cement were also apparent in phagocytes. In another study, mineral grains had become detached from the cement and some of them had been phagocytosed by macrophages. These grains were round in shape and did not exceed $12 \mu \mathrm{m}$ [14].

Orthopedic implant studies have highlighted that wear particles could induce an inflammatory response $[15,16]$ or could alter the osteoblast functions $[17,18]$ if their size was smaller than $10 \mu \mathrm{m}$. It will then be important to verify the CPC biocompatibility not only in a bulk form, but also in a particulate form of micrometer size.

Few studies have been performed with CPC particles smaller than $10 \mu \mathrm{m}$. An in vivo study using mice has shown that CPC particles of around $10 \mu \mathrm{m}$ could be degraded by macrophages or multinucleated giant cells [19]. This degradation process produced an accumulation of calcium in mitochondria and finally led to lysis of mitochondria and cell death [19]. Very little information is actually available on reaction of osteoblasts to CPC particles. It has been shown that hydroxyapatite particles smaller than $10 \mu \mathrm{m}$ reduced osteoblast growth and alkaline phosphatase activity [20]. The inhibition of osteoblast growth was confirmed when these cells were co-cultured with submicron calcium phosphate particles at a concentration of $1 \mathrm{~g} / 1$ [21]. An increase of prostaglandin $\mathrm{E}_{2}$ production, a potential osteolytic factor, was also measured [21]. If CPC particles adversely affect the osteoblast functions as these studies suggested, bone formation will be delayed until the particles are completely resorbed. Further investigations should be performed to clarify the reaction of osteoblasts to CPC particles. In particular, a dose-dependent effect on osteoblast viability or proliferation, a quantification of extracellular matrix proteins production or the reaction of osteoblasts to CPC particles of different sizes should be established. Investigations of CPC particles effect on osteoblasts should also be performed in the presence of cytokines as interleukin-6 (IL-6) or tumor necrosis factor- $\alpha(\mathrm{TNF}-\alpha)$ as these agents were detected when particles of orthopedic implants were present [22,23].

The in vitro and in vivo resorption of $\mathrm{CPC}$ has been well documented allowing this material to be character- ized as biodegradable. Bone ingrowth should also be enhanced, or at least not altered, to quickly achieve a stable mechanical situation. The effect of CPC on osteoblasts should then be extensively detailed. Especially in the situation where particles are present, the osteoblast functions should be quantified. The aim of this study was to assess the behavior of osteoblasts contacted by $\beta$-TCP, brushite and cement particles. The cement used in this study was composed of $91 \mathrm{wt} \%$ brushite and $9 \mathrm{wt} \% \beta$-TCP. Two sizes of particles were prepared, one corresponding to the critical range $(1-10 \mu \mathrm{m})$ and the other corresponding to a diameter larger than $10 \mu \mathrm{m}$.

\section{Materials and methods}

\subsection{Calcium phosphate cement particles}

\subsubsection{Generation}

Three powder compositions were prepared: brushite, $\beta$-TCP and brushite cement which is a mixture of brushite and $\beta$-TCP. Powders name and composition are reported in Table 1. For each powder composition, two size distributions were obtained by powder grinding and sieving. $\beta$-TCP granules were obtained by drying a suspension in a Büchi Mini Spray Dryer 190. $\beta$-TCP powder used in the suspension was synthesized in the laboratory and has a $\mathrm{Ca} / \mathrm{P}$ ratio of 1.47 to ensure $\beta$-TCP purity [24]. Large size granules $\left(\beta_{\mathrm{L}}\right)$ were collected from the bottom of the drying column. Small granules $\left(\beta_{\mathrm{S}}\right)$ were recovered in the collector. After drying, the granules were sintered at $900^{\circ} \mathrm{C}$ for $4 \mathrm{~h}$. DCPD was prepared with a commercial powder (Fluka, ref. 21184). Large size powder $\left(D_{L}\right)$ is the as-received commercial powder. Small size powder $\left(D_{S}\right)$ is obtained by grinding the commercial DCPD in a ball mill with zirconia balls in the presence of water. For this operation, $500 \mathrm{ml}$ polyethylene jar was placed in the ball mill at $111 \mathrm{rpm}$ for $2 \mathrm{~h}$. Then, the powder was dried by lyophilization. Brushite cement powders were prepared by grinding cement blocks as explained hereafter. One $\mathrm{cm}^{3}$ of cement paste was obtained by mixing $1.2 \mathrm{~g}$ $\beta$-TCP, $0.8 \mathrm{~g}$ monocalcium phosphate monohydrate,

Table 1

Physical and chemical characterizations of the CPC particles used. The size distribution was measured by laser diffraction (Malvern). $d_{10}, d_{50}$, $d_{90}$ mean that $10,50,90 \%$ of the particles have a size smaller than the given size

\begin{tabular}{|c|c|c|c|c|c|c|}
\hline Name & Composition & Chemical formulation & $\begin{array}{l}\text { Density } \\
\left(\mathrm{g} / \mathrm{cm}^{3}\right)\end{array}$ & $\begin{array}{l}d_{10} \\
(\mu \mathrm{m})\end{array}$ & $\begin{array}{l}d_{50} \\
(\mu \mathrm{m})\end{array}$ & $\begin{array}{l}d_{90} \\
(\mu \mathrm{m})\end{array}$ \\
\hline$\beta_{\mathrm{L}}$ & $\beta$-TCP granules & $\mathrm{Ca}_{3}\left(\mathrm{PO}_{4}\right)_{2}$ & 3.07 & 3.81 & 29.15 & 65.44 \\
\hline $\mathrm{C}_{\mathrm{L}}$ & Cement & $\mathrm{DCPD} / \beta-\mathrm{TCP}=91 / 9(\mathrm{wt} \%)$ & 2.36 & 1.57 & 28.47 & 74.03 \\
\hline$\beta_{\mathrm{S}}$ & $\beta$-TCP granules & $\mathrm{Ca}_{3}\left(\mathrm{PO}_{4}\right)_{2}$ & 3.07 & 0.79 & 5.10 & 14.25 \\
\hline $\mathrm{D}_{\mathrm{S}}$ & DCPD & $\mathrm{CaHPO}_{4} 2 \mathrm{H}_{2} \mathrm{O}$ & 2.31 & 1.03 & 6.35 & 19.50 \\
\hline
\end{tabular}


$0.015 \mathrm{~g} \mathrm{Na}_{2} \mathrm{H}_{2} \mathrm{P}_{2} \mathrm{O}_{7}$ and $0.8 \mathrm{ml} \mathrm{H}_{2} \mathrm{SO}_{4}(0.1 \mathrm{M})$. $\beta$-TCP was synthesized in the laboratory [24], monocalcium phosphate monohydrate was purchased from Albright \& Wilson (Richmond, VA) and $\mathrm{Na}_{2} \mathrm{H}_{2} \mathrm{P}_{2} \mathrm{O}_{7}$ was purchased from Fluka (ref. 7150). Cement cylinders were moulded in syringes. After cement setting, they were broken manually in a mortar to obtain fragments. Large size powder $\left(\mathrm{C}_{\mathrm{L}}\right)$ was prepared by grinding manually the fragments in a mortar. Powder in the size range between 20 and $100 \mu \mathrm{m}$ was collected by successive sieving and grinding operations. Small size powder $\left(\mathrm{C}_{\mathrm{S}}\right)$ was prepared by grinding the fragments in a ball mill with zirconia balls in the presence of water. For this, $500 \mathrm{ml}$ polyethylene jar was placed in the ball mill at $111 \mathrm{rpm}$ for $1 \mathrm{~h}$. Finally, the powder was dried by lyophilization.

\subsubsection{Characterization}

Powder mineralogical phase was controlled by X-ray diffraction. X-ray diffraction measurements were performed on a Siemens Kristalloflex 805 diffractometer, by using the $\mathrm{Cu}-\mathrm{Ka}$ line, between 20 and $40^{\circ}$ at an angular sweeping rate of $0.01^{\circ}(2 \theta) / \mathrm{s}$. $\beta$-TCP prepared in the laboratory was almost pure. Commercial DCPD contains a small quantity of monetite $\left(\mathrm{CaHPO}_{4}\right)$. Theoretical cement composition is $91 \mathrm{wt} \%$ brushite and $9 \mathrm{wt} \%$ $\beta$-TCP, but a small amount of monetite was detected as well.

Volume particle size distributions were performed with laser diffraction by using Malvern MasterSizer equipment. Fine powders have a natural tendency to agglomerate during storage. For this reason, the powders were ultrasonically dispersed in water for $10 \mathrm{~min}$ before particle size measurements. The values obtained for the different powders are given in Table 1. Particle size and morphology were characterized by SEM micrographs. The different powders are illustrated in Fig. 1. The agglomeration states of the powders are also highlighted by these pictures. $\beta$-TCP particles have a spherical shape due to the drying technique while DCPD and cement particles obtained by grinding present angular shapes.

The specific surface area $\left(S_{\mathrm{BET}}\right)$ of the powder was measured by $\mathrm{N}_{2}$ adsorption with a Micromeritics apparatus using the BET model. The measured values are summarized in Table 2. Equivalent BET diameter was calculated from the experimental $S_{\mathrm{BET}}$. The agglomeration factor $\mathrm{AgF}$ is defined as $d_{50} / d_{\mathrm{BET}}$. This ratio evaluates the number of particle in an agglomerate.

\subsubsection{Preparation of the particles for the experiments}

The particles, sterilized by gamma irradiation, were mixed with the culture medium under sterile conditions. Based on a particle weight to medium volume ratio, different concentrations of particles were prepared. Con- centrations of $0.001,0.01$, and $0.1 \%$ of particles corresponded to $0.01,0.1$, and $1.0 \mathrm{mg}$ of particles per $\mathrm{ml}$ of medium. Based on the size distribution of the different particles, the number of particles in $1 \mathrm{ml}$ of the $0.1 \%$ concentration is reported in Table 3. The particle solutions were ultrasonicated for $10 \mathrm{~min}$ in a sealed sterile container to minimize the agglomeration of the particles before being added to the cell culture. It was verified in preliminary tests that for all the concentrations used in this study, the CPC particles did not influence the $\mathrm{pH}$ value of the culture medium (data not shown).

\subsection{Cell cultures}

\subsubsection{Osteoblast}

Neonatal Sprague-Dawley calvarial rat were used to obtain osteoblasts following the procedure reported by Puleo [18]. The isolated osteoblasts were cultured in monolayer at $37^{\circ} \mathrm{C}$ and $5 \% \mathrm{CO}_{2}$ in Dulbecco's Modified Eagle Medium (Irvine Scientific, Santa Ana, CA) containing $10 \%$ of fetal bovine serum (Irvine Scientific,), 2\% L-glutamin (BioWhittaker, Walkersville, MD) and $1 \%$ of PSF $(100 \times, 10000 \mathrm{U} / \mathrm{ml}$ Penicillin, $10000 \mathrm{UG} / \mathrm{ml}$ strepzin, $25 \mathrm{UG} / \mathrm{ml}$ Fungizone; BioWhittaker). These cells were characterized as being of osteoblastic phenotype by testing for the formation of calcium phosphate salts using the von Kossa staining technique (data not shown) which is an indication of osteoblast mineralization [25] and by the presence of alkaline phosphatase [18]. Osteocalcin, another marker of osteoblast phenotype [26], was detected by EIA kit (Biomedical Technology, Stoughton, MA) when osteoblasts were cultured with vitamin $\mathrm{D}_{3}$ (CalBiochem, San Diego, CA) (data not shown). Furthermore, the cells displayed the elongated polygonal morphology typical of osteoblasts in culture. We checked that the osteoblast phenotype defined by the above markers was maintained until at least passage 6. Osteoblasts of passage 3-6 were used for the experiments. If not otherwise indicated, cells were plated in 24 or in 96 well plates at a concentration of $5 \times 10^{5}$ cells $/ \mathrm{cm}^{2}$.

\subsubsection{Fibroblasts}

In order to check if the particles at low concentrations can induce proliferation of fibroblasts which can promote the creation of fibrous membrane surrounding the cement, we co-cultured fibroblasts with CPC particles. Fibroblasts from the cell line HS-68 (American Type Culture Collection, Rockville, MD) were cultured in monolayer at $37^{\circ} \mathrm{C}$ and $5 \% \mathrm{CO}_{2}$ in Dulbecco's Modified Eagle Medium (DMEM, Irvine Scientific, Santa Ana, CA) containing $10 \%$ of fetal bovine serum (Irvine Scientific, Santa Ana, CA), 1\% of PSF $(100 \times, 10000 \mathrm{U} / \mathrm{ml}$ Penicillin, $10000 \mathrm{UG} / \mathrm{ml}$ strepzin, $25 \mathrm{UG} / \mathrm{ml}$ Fungizone; BioWhittaker, Walkersville, MD), and 1\% of non-essential amino acid (BioWhittaker, Walkersville, MD). Cells 
$\beta_{\mathrm{L}}$

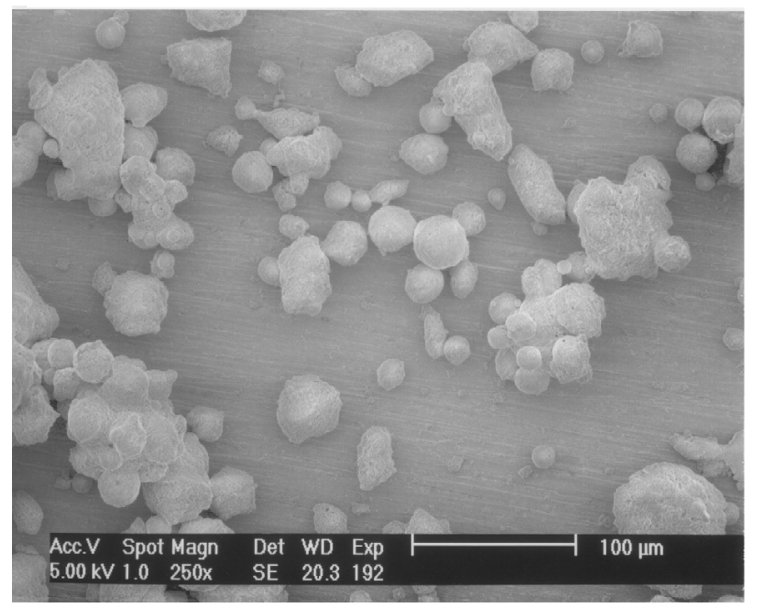

$\mathrm{D}_{\mathrm{L}}$

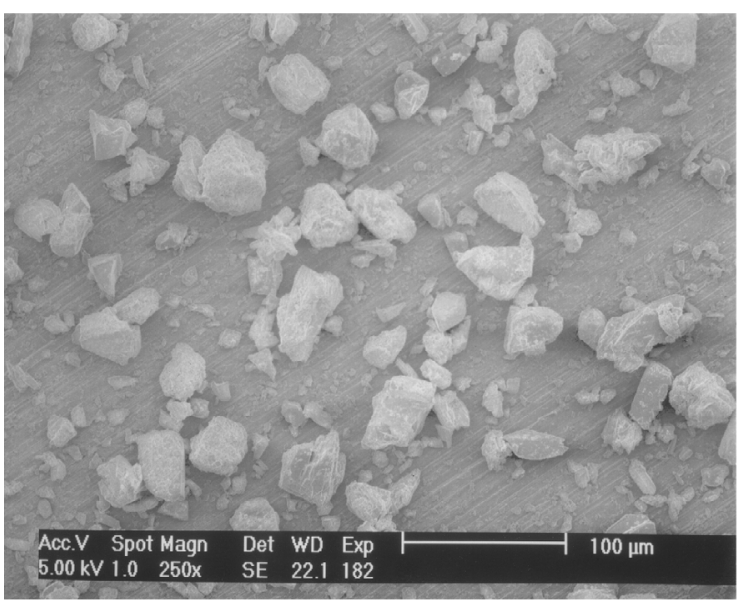

$\mathrm{C}_{\mathrm{L}}$

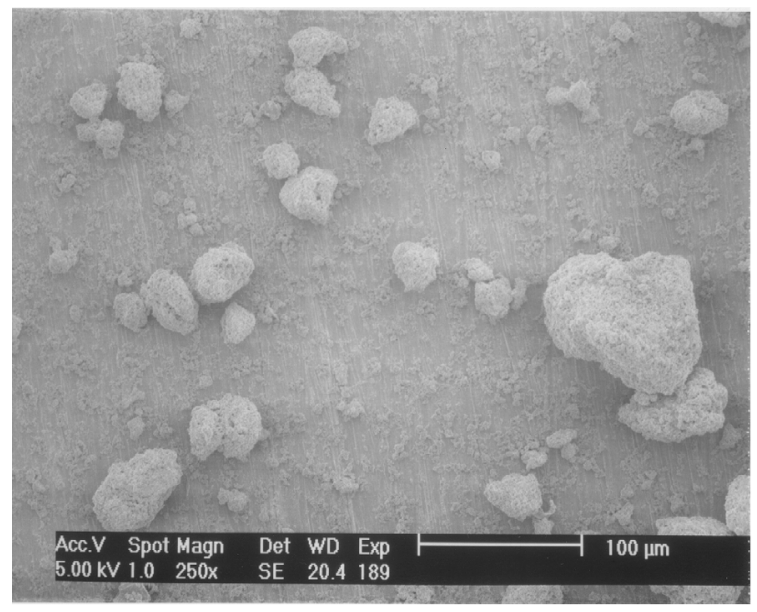

$\beta_{S}$

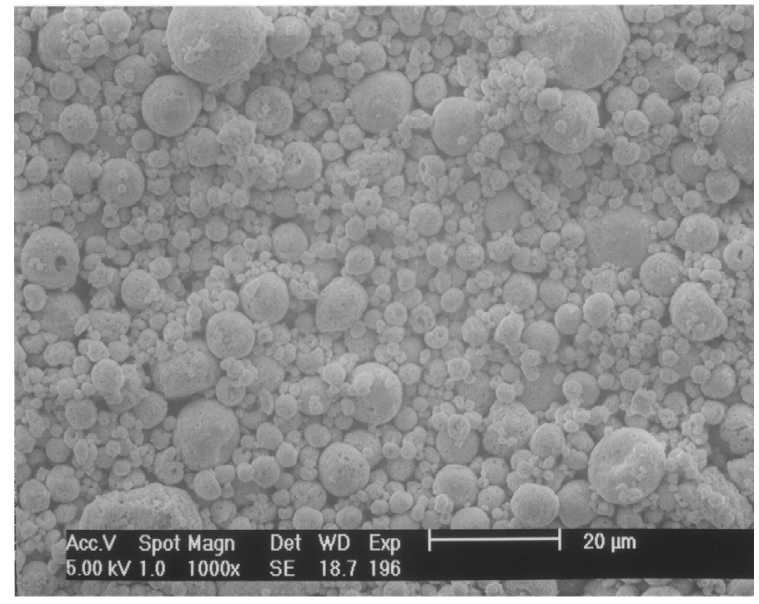

$\mathrm{D}_{\mathrm{S}}$

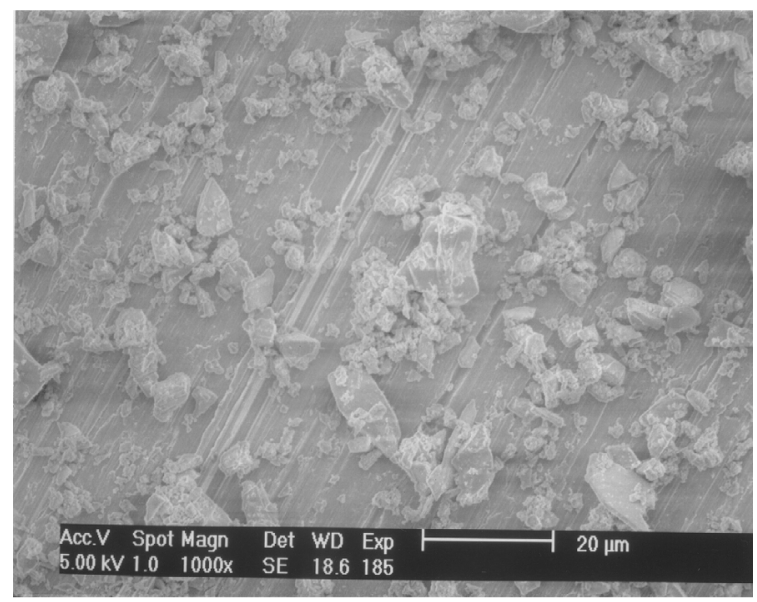

$\mathrm{C}_{\mathrm{S}}$

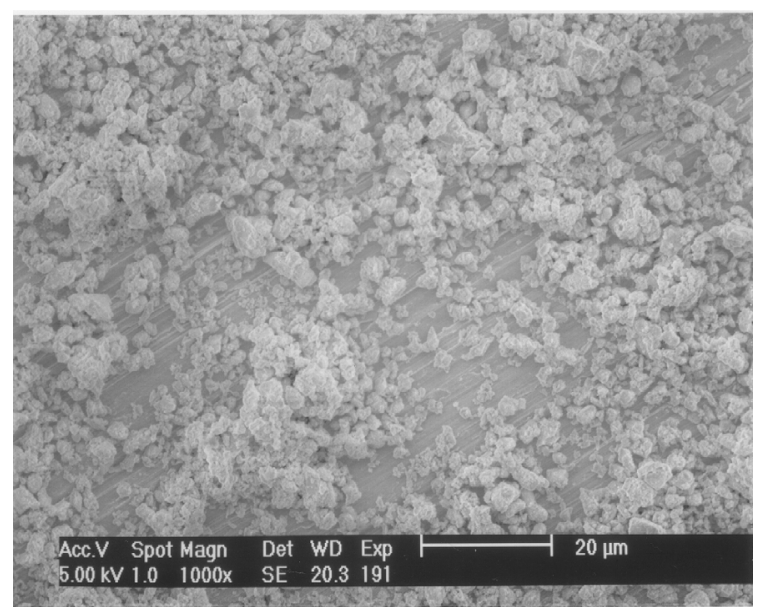

Fig. 1. SEM pictures of CPC particles $\beta_{\mathrm{L}}, \beta_{\mathrm{S}}, \mathrm{D}_{\mathrm{L}}, \mathrm{D}_{\mathrm{S}}, \mathrm{C}_{\mathrm{L}}$ and $\mathrm{C}_{\mathrm{S}}$. 
Table 2

$S_{\mathrm{BET}}$, equivalent BET diameter $\left(d_{\mathrm{BET}}\right)$ and agglomeration factor $(\mathrm{AgF})$ of the powders

\begin{tabular}{llrrr}
\hline Name & Composition & $\begin{array}{l}S_{\mathrm{BET}} \\
\left(\mathrm{m}^{2} / \mathrm{g}\right)\end{array}$ & $\begin{array}{l}d_{\mathrm{BET}} \\
(\mu \mathrm{m})\end{array}$ & $\mathrm{AgF}$ \\
\hline$\beta_{\mathrm{L}}$ & $\beta$-TCP granules & 2.63 & 0.74 & 39.4 \\
$\mathrm{D}_{\mathrm{L}}$ & DCPD & 1.87 & 1.39 & 10.5 \\
$\mathrm{C}_{\mathrm{L}}$ & Cement & 3.53 & 0.72 & 39.5 \\
$\beta_{\mathrm{S}}$ & $\beta$-TCP granules & 2.95 & 0.66 & 7.7 \\
$\mathrm{D}_{\mathrm{S}}$ & DCTP & 4.54 & 0.57 & 11.1 \\
$\mathrm{C}_{\mathrm{S}}$ & Cement & 10.03 & 0.25 & 10.0 \\
\hline
\end{tabular}

Table 3

Number of particles in $1 \mathrm{ml}$ of $0.1 \%$ solution for the six different particles used

\begin{tabular}{llllll}
\hline$\beta_{\mathrm{L}}$ & $\mathrm{D}_{\mathrm{L}}$ & $\mathrm{C}_{\mathrm{L}}$ & $\beta_{\mathrm{S}}$ & $\mathrm{D}_{\mathrm{S}}$ & $\mathrm{C}_{\mathrm{S}}$ \\
\hline $0.02 \times 10^{6}$ & $0.23 \times 10^{6}$ & $0.03 \times 10^{6}$ & $6.6 \times 10^{6}$ & $3.2 \times 10^{6}$ & $51.7 \times 10^{6}$ \\
\hline
\end{tabular}

were plated in 24 well plates at a concentration of $6 \times 10^{3} \mathrm{cells} / \mathrm{cm}^{2}$.

\subsection{Osteoblasts viability}

The cells were collected by trypsinization and were simultaneously double stained for $5 \mathrm{~min}$ at room temperature using fluorescein diacetate and propidium iodide stains (Sigma, St. Louis, MO) [27]. The stained cells were examined with an inverted fluorescent microscope (Nikon, Tokyo, Japan) equipped with epi-illumination (blue filter of $495 \mathrm{~nm}$ and green filter of $546 \mathrm{~nm}$ allowed visualization of the green and red fluorescing cells, respectively). The solution of stained cells was vortexed before counting, leading to a homogeneous distribution of green and red cells in each sample. A minimum of 200 viable (green)/non-viable (red) cells were counted for each measurement. Viability was defined as the ratio of viable cells to the total number of cells [(number of green cells/(number of green + number of red cells))].

\subsubsection{Dose, size, time and composition effects}

After the osteoblasts were incubated for $4 \mathrm{~h}$ in 24 well plates to recover from post-trypsinization, the medium was removed. One $\mathrm{ml}$ of new medium (in control wells) and $1 \mathrm{ml}$ of various particle types solution $\left(\beta_{\mathrm{L}}, \mathrm{D}_{\mathrm{L}}, \mathrm{C}_{\mathrm{L}}\right.$, $\left.\beta_{\mathrm{S}}, \mathrm{D}_{\mathrm{S}}, \mathrm{C}_{\mathrm{S}}\right)$ at different concentrations $(0.001,0.01$, and $0.1 \%$ ) were added. The cells were incubated for 24,48 , $72 \mathrm{~h}$ and their viability was measured.

\subsubsection{Inflammatory cytokine effects}

Osteoblasts were co-incubated without (defining the control group) or with CPC particles $\mathrm{C}_{\mathrm{S}}$ at concentra- tions of $0.001,0.01$, and $0.1 \%$ in 96 well plates. Two inflammatory agents, IL-6 (Sigma, St.-Louis, MO) and TNF- $\alpha$ (Sigma, St.-Louis, MO) at concentrations $1,10,100 \mathrm{ng} / \mathrm{ml}$ were added with the particles. The viability of each sample was measured after $72 \mathrm{~h}$ of incubation.

\subsubsection{Indirect effects}

After the osteoblasts without (defining the control group) or with CPC particles $\left(\beta_{\mathrm{L}}, \mathrm{D}_{\mathrm{L}}, \mathrm{C}_{\mathrm{L}}, \beta_{\mathrm{S}}, \mathrm{D}_{\mathrm{S}}, \mathrm{C}_{\mathrm{S}}\right)$ at $0.1 \%$ concentration were incubated for $72 \mathrm{~h}$, in parallel to the viability measurement, the supernatant of each well was individually collected and centrifuged for $5 \mathrm{~min}$ at $500 \mathrm{~g}$ (to avoid the contamination of the supernatant by particles). A second group of osteoblasts was incubated for $4 \mathrm{~h}$ in 24 well plates and the medium was removed in each well. The collected supernatant from the first osteoblast group was then used as the culture medium. The second cell group, cultured with the conditioned medium, was incubated for $72 \mathrm{~h}$ and its viability was measured.

\subsection{Osteoblasts proliferation}

The proliferation of osteoblasts plated in 24 well plates at a concentration of $1 \times 10^{4}$ cells $/ \mathrm{cm}^{2}$ and co-cultured for $72 \mathrm{~h}$ without (defining the control group) or with CPC particles $\left(\beta_{\mathrm{L}}, \mathrm{D}_{\mathrm{L}}, \mathrm{C}_{\mathrm{L}}, \beta_{\mathrm{S}}, \mathrm{D}_{\mathrm{S}}, \mathrm{C}_{\mathrm{S}}\right)$ at concentrations of $0.001,0.01$, and $0.1 \%$ was evaluated by counting the cells on a hemacytometer after trypsinization. The data were normalized with the proliferation value of the control group.

\subsection{Type I collagen and fibronectin mRNA expression}

Osteoblasts were plated in $100 \mathrm{~mm}$ petri dish at a concentration of $5 \times 10^{5}$ cells $/ \mathrm{cm}^{2}$ and incubated for $24 \mathrm{~h}$. The medium was removed and new medium without serum was added. The incubation was continued for $24 \mathrm{~h}$. The medium deprived of serum was then removed and $0.5 \%$ serum medium without (defining the control group) or with CPC particles $\left(\beta_{\mathrm{L}}, \mathrm{D}_{\mathrm{L}}, \mathrm{C}_{\mathrm{L}}, \beta_{\mathrm{S}}, \mathrm{D}_{\mathrm{S}}, \mathrm{C}_{\mathrm{S}}\right)$ at a concentration of $0.01 \%$ was added to the cells and incubated for $24 \mathrm{~h}$. Relative changes in the levels of messenger RNA (mRNA) for type I collagen and fibronectin were assessed by Northern blot analysis. Total RNA was isolated and purified by a modified guanidinium thiocyanate phenol-chloroform extraction technique, separated by $1 \%$ agarose-formaldehyde gel electrophoresis, and transferred onto nitrocellulose. Samples were adjusted by assessment of $28 \mathrm{~S}$ band intensity using ethidium bromide so that approximately equal amounts of total RNA were loaded into each well. Membranes were then hybridized with cDNA probes radiolabeled by the random primers technique, washed, and exposed to autoradiograph film. Levels of mRNA were normalized 
by intensities of ethidium bromide luminescence for $28 \mathrm{~S}$ rRNA under UV exposure to correct for small loading differences.

\subsection{Alkaline phosphatase (ALP) production}

ALP activity was determined using an ALP kit (Diagnostic kit 245, Sigma, St. Louis, MO). Cells were plated in 24 well culture plates with $0.5 \mathrm{ml}$ of complete medium (medium described in Section 2.2.1 supplemented with $50 \mu \mathrm{g} / \mathrm{ml}$ ascorbic acid (Sigma) and $10 \mathrm{~mm}$ $\beta$-glycerol phosphate (Sigma)). After $24 \mathrm{~h}$, culture medium was replaced by fresh media deprived of serum without (defining the control group) or with CPC particles $\left(\mathrm{C}_{\mathrm{L}}, \mathrm{C}_{\mathrm{S}}\right)$ at concentrations of $0.001,0.01$ and $0.1 \%$. The cells were cultured for another $48 \mathrm{~h}$, the medium was then removed and the cells were rinsed three times with PBS followed by addition of $0.5 \mathrm{ml}$ Triton-X 100 $(1 \%)$. After freezing and thawing, the cell lysates were sonicated for $1 \mathrm{~min}$ on ice. The cell lysates were centrifuged and a volume of $20 \mu \mathrm{l}$ of each sample was added to $100 \mu \mathrm{l}$ of $p$-Nitrophenyl phosphate solution within a 96 well plate at $25^{\circ} \mathrm{C}$ and reacted for 3 min. $p$-Nitrophenol was produced in the presence of ALP and the absorbance could be measured with a microplatereader at $405 \mathrm{~nm}$. The change in the rate of absorbance was directly proportional to the ALP activity. Data were normalized by the total cell protein measured with a commercial kit (DC protein Assay Kit, Bio-Rad, Hercules, CA).

\subsection{Fibroblasts proliferation}

The proliferation of fibroblasts co-cultured for $72 \mathrm{~h}$ without (defining the control group) or with the CPC particles $\left(\beta_{\mathrm{L}}, \mathrm{D}_{\mathrm{L}}, \mathrm{C}_{\mathrm{L}}, \beta_{\mathrm{S}}, \mathrm{D}_{\mathrm{S}}, \mathrm{C}_{\mathrm{S}}\right)$ at concentrations of $0.001,0.01$, and $0.1 \%$ was evaluated by counting the cells on a hemacytometer after trypsinization. The data were normalized with the proliferation value of the control group.

\subsection{Statistical analysis}

Northern blot tests were performed three times while all the other experiments were performed three times in triplicates, yielding essentially identical results. A oneway ANOVA test was used to analyze the mean variance of the data for the indirect effect, and the gene expression. A two-way ANOVA test was used to analyze the mean variance of the data for the viability, the proliferation and the alkaline phosphatase. If statistically significant differences were found with the ANOVA test, a Fisher least significant difference test was performed to determine which means were different from which other means. A $95 \%$ confidence level was selected to define significance for all statistical tests.

\section{Results}

\subsection{Osteoblasts viability}

\subsubsection{Dose, size, time and composition effects}

The viability of the osteoblasts was affected by CPC particles in a dose-dependent manner (Fig. 2). The coculture of osteoblasts with the highest particle concentration $(0.1 \%)$ significantly decreased viability when compared to control and to the two lower particle concentrations $(0.001 \%, 0.01 \%) \quad(P<0.0001)$. The small CPC particle sizes $\left(\beta_{\mathrm{S}}, \mathrm{D}_{\mathrm{S}}, \mathrm{C}_{\mathrm{S}}\right)$ were statistically more harmful for the osteoblasts viability than the large ones $\left(\beta_{\mathrm{L}}, \mathrm{D}_{\mathrm{L}}, \mathrm{C}_{\mathrm{L}}\right)(P<0.0001)$. There was no effect of composition between the large particle sizes, while a statistical effect on osteoblasts viability existed between the composition of the small CPC particle sizes $(P<0.05)$. The CPC particles $\mathrm{C}_{\mathrm{S}}$ were the most harmful for the osteoblasts viability. All these observations were verified at three time points $(24,48$, and $72 \mathrm{~h}$ ) (Fig. 2a-c).

\subsubsection{Inflammatory cytokine effects}

There was no additive or direct effect of the two inflammatory cytokines tested (IL-6, TNF- $\alpha$ ) for $72 \mathrm{~h}$ on the osteoblasts viability (Fig. 3). It was verified that the $0.1 \%$ concentration of $\mathrm{C}_{\mathrm{S}}$ had a strong statistical effect on osteoblasts viability $(P<0.0001)$.

\subsubsection{Indirect effects}

There was no statistical effect on osteoblast viability using the conditioned medium (Fig. 4). No cytokine or release of agent at a level harmful for the osteoblasts was produced by the osteoblasts in contact with CPC particles.

\subsection{Osteoblasts proliferation}

A decrease of osteoblasts proliferation for all particle types and concentrations higher than $0.001 \%$ was observed compared to control $(P<0.01)$ (Fig. 5). There was a strong dose-dependent effect, the highest concentration being the most inhibitory for the osteoblasts proliferation $(P<0.001)$. Except for the DCPD particles, a size effect was noted, the small particle sizes being the most inhibitory for the osteoblasts proliferation $(P<0.02)$. A composition effect was noted between all but the $\mathrm{D}_{\mathrm{L}}, \mathrm{C}_{\mathrm{L}}$ and $\beta_{\mathrm{S}}, \mathrm{C}_{\mathrm{S}}$ couples $(P<0.04)$.

\subsection{Type I collagen and fibronectin mRNA expression}

Turning to the gene expression, a decrease of mRNA level for type I collagen was observed for $\beta_{\mathrm{S}}(P<0.02)$ and $\mathrm{C}_{\mathrm{S}}(P<0.0004)$ compared to control (Fig. 6a). A size effect was noted only for the $\mathrm{C}$ particles $(P<0.001)$. An increase of mRNA level for fibronectin was observed for 

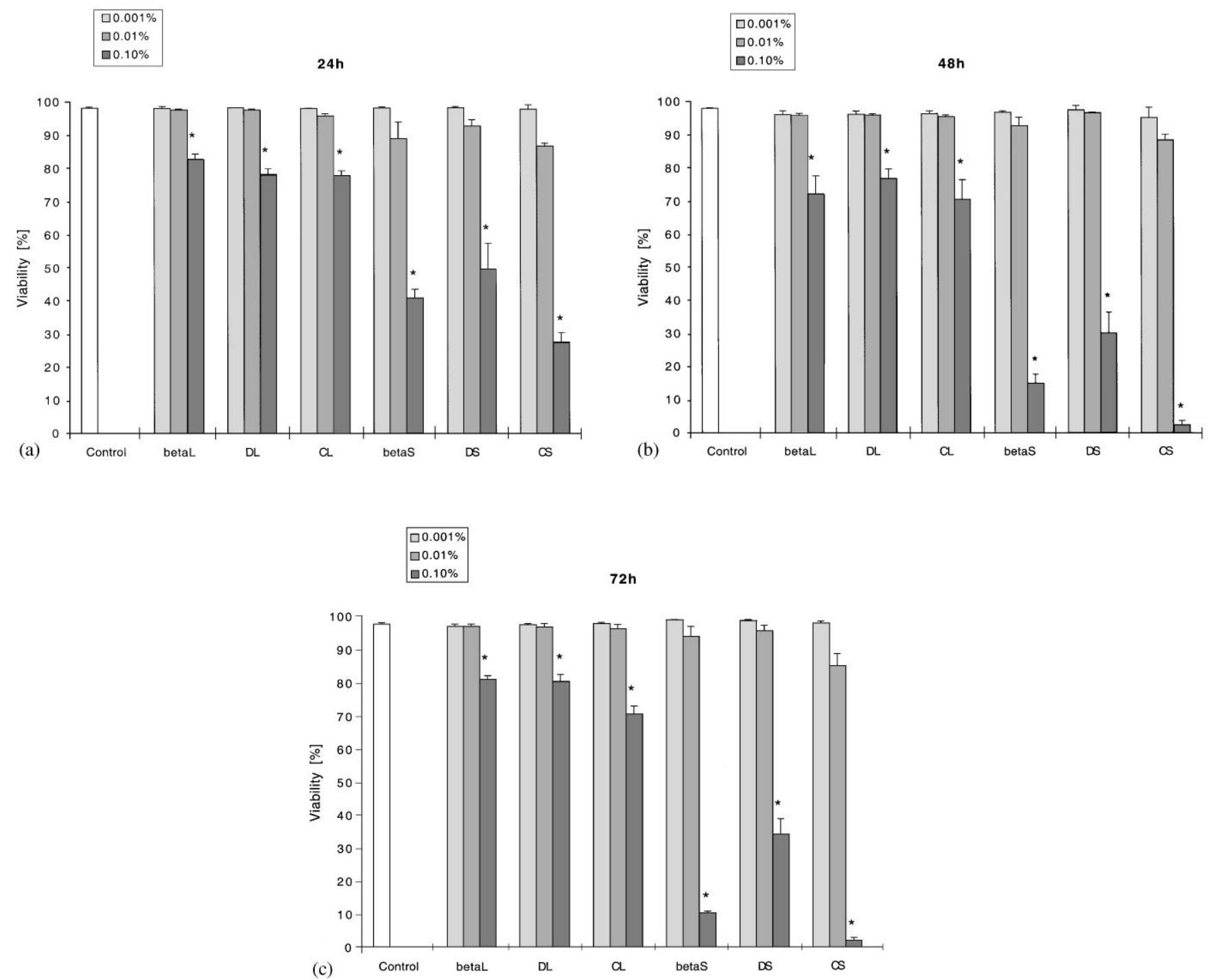

Fig. 2. Dose, size, time and composition effects of the CPC particles on osteoblasts viability (a) $24 \mathrm{~h}$; (b) $48 \mathrm{~h}$; (c) $72 \mathrm{~h}$ (mean value \pm SE). A statistical difference was found between the different doses, the size and the material (for details see text). The particles $\mathrm{C}_{\mathrm{S}}$ were the most harmful for the osteoblasts viability ( $*$ : statistical differences with respect to control, $n=9$ and $P<0.0001$ ).

$\beta_{\mathrm{L}}(P<0.02)$ compared to control (Fig. 6b). There was a statistical decrease of mRNA level for fibronectin with the small particle sizes $\left(\beta_{\mathrm{S}}, \mathrm{D}_{\mathrm{S}}, \mathrm{C}_{\mathrm{S}}\right)$ compared to the large ones $\left(\beta_{\mathrm{L}}, \mathrm{D}_{\mathrm{L}}, \mathrm{C}_{\mathrm{L}}\right)$.

\subsection{Alkaline phosphatase production}

An increase in ALP production was found for particles $\mathrm{C}_{\mathrm{L}}$ compared to control (Fig. 7). A concentration effect was also noted $(P<0.002)$.

\subsection{Fibroblasts proliferation}

The proliferation of fibroblasts was inhibited by the three small CPC particles $(P<0.01)$ (Fig. 8). A dose dependence was noted, the most inhibitory effect being induced by the highest concentration $(P<0.01)$.

\section{Discussion}

This study was performed to quantify the osteoblast reaction contacted by different types of CPC particles. We found that the CPC particles had dose-dependent effects on osteoblasts viability, proliferation, and alkaline phosphatase production as well as on fibroblasts proliferation. Particle concentrations should not exceed $0.01 \%$, corresponding for the $\mathrm{C}_{\mathrm{S}}$ particles of 50 particles per osteoblast. There was a size effect on osteoblasts viability, proliferation, and gene expression, as well as on 

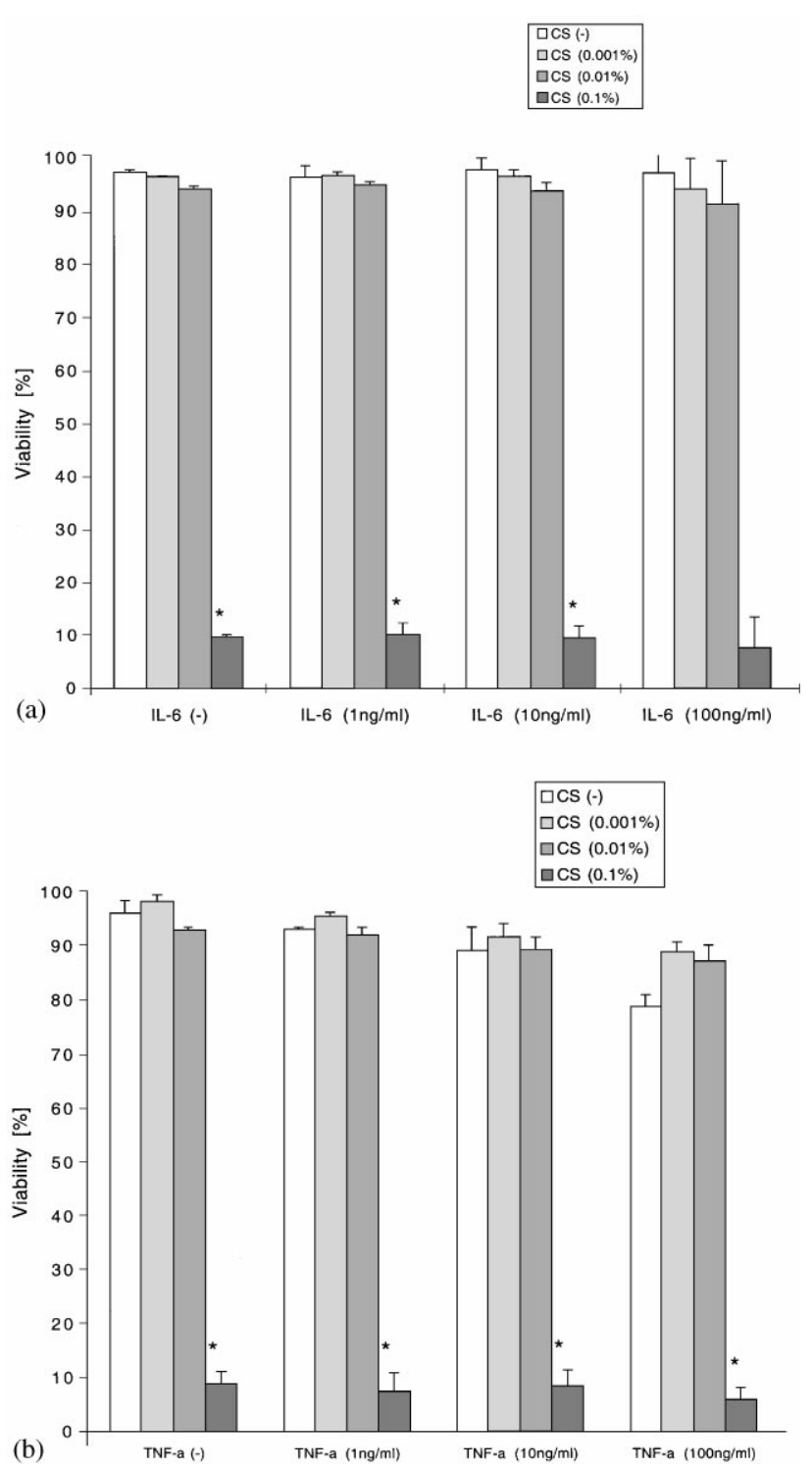

Fig. 3. Effects of inflammatory cytokines (a) IL-6, (b) TNF- $\alpha$ and CPC particles on osteoblasts viability after $72 \mathrm{~h}$ (mean value $\pm \mathrm{SE}$ ). No direct or additive effect of the two inflammatory cytokines was found on the osteoblasts viability (*: statistical differences with respect to control, $n=9$ and $P<0.0001)$.

fibroblasts proliferation. With the parameters measured in this study, it appeared that the small particles were less biocompatible than the large ones. Moreover, between the small particles, a composition effect was noted on the osteoblasts viability and proliferation. The $\mathrm{C}_{\mathrm{S}}$ particles were the less biocompatible. Inflammatory cytokines seemed not to be a parameter that could influence these results, at least for the osteoblasts viability.

The dose-dependent response of osteoblasts to particles has already been noted for cobalt [28] or titanium particles [17], but was not well established for CPC particles. The shape of the particles (round for $\beta$-TCP and with angular shapes for the others) was not a para-

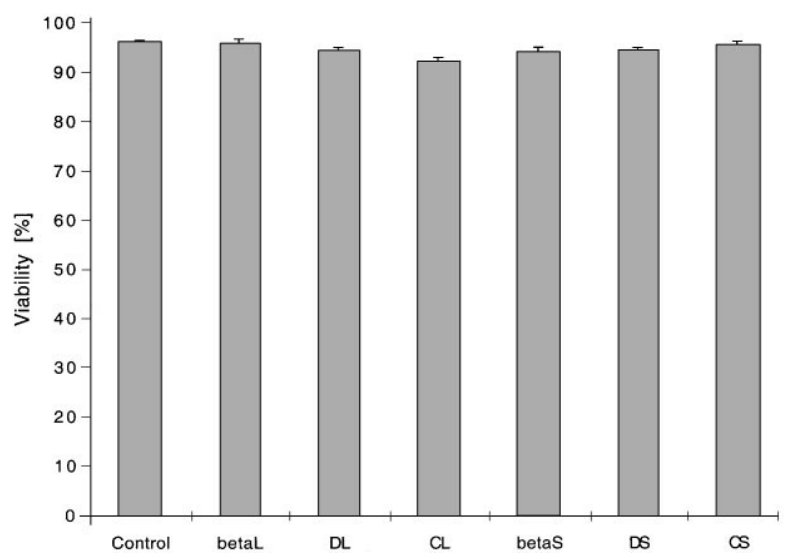

Fig. 4. Indirect effect of CPC particle on osteoblasts viability using the conditioned medium of the $0.1 \%$ culture (mean value $\pm \mathrm{SE}, n=9$ ). No indirect effect was noted on the osteoblasts viability using the conditioned medium issued from the $72 \mathrm{~h}$ co-incubation of particles with osteoblasts.

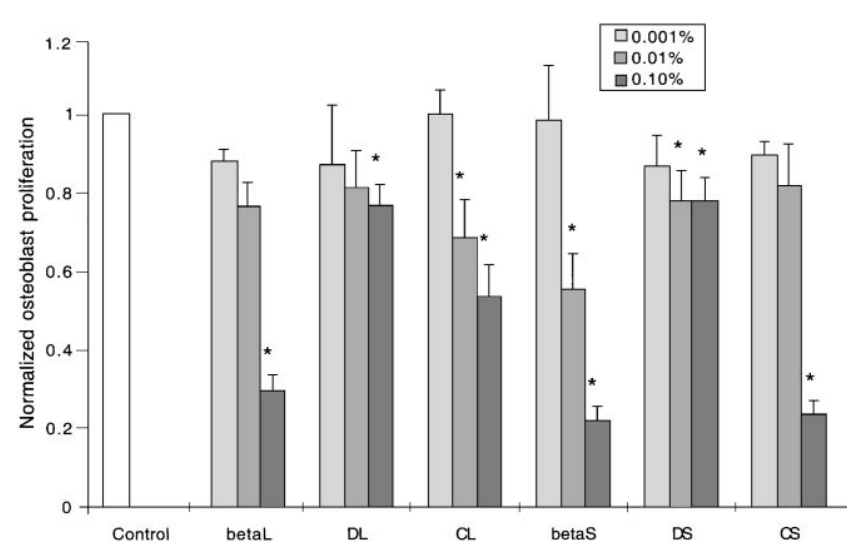

Fig. 5. Dose, size and material effects of the CPC particles on osteoblasts proliferation after $72 \mathrm{~h}$ (mean value $\pm \mathrm{SE}$ ). A statistically significant decrease of proliferation was found for all particle types and concentrations (*: statistical differences with respect to control, $n=9$ and $P<0.01)$.

meter that influenced the osteoblast functions (data not shown). The small CPC particles induced an important negative effect on osteoblast functions which strongly suggested that the phagocytosis process of CPC particles was involved. Recent findings that osteoblasts phagocytosed Ti particles [29] and osteoblasts treated with cytochalasin-D (agent that inhibits phagocytosis by affecting actin filament assembly of the cytoskeleton) almost completely suppressed the negative effect of $\mathrm{Ti}$ particle on osteoblast viability [17] supports this hypothesis. As for the macrophages or multinucleated giant cells [19], this phagocytosis process could produce an accumulation of calcium in mitochondria and could eventually lead to lysis of mitochondria and cell death. Impact of CPC particles on osteoblast functions could 


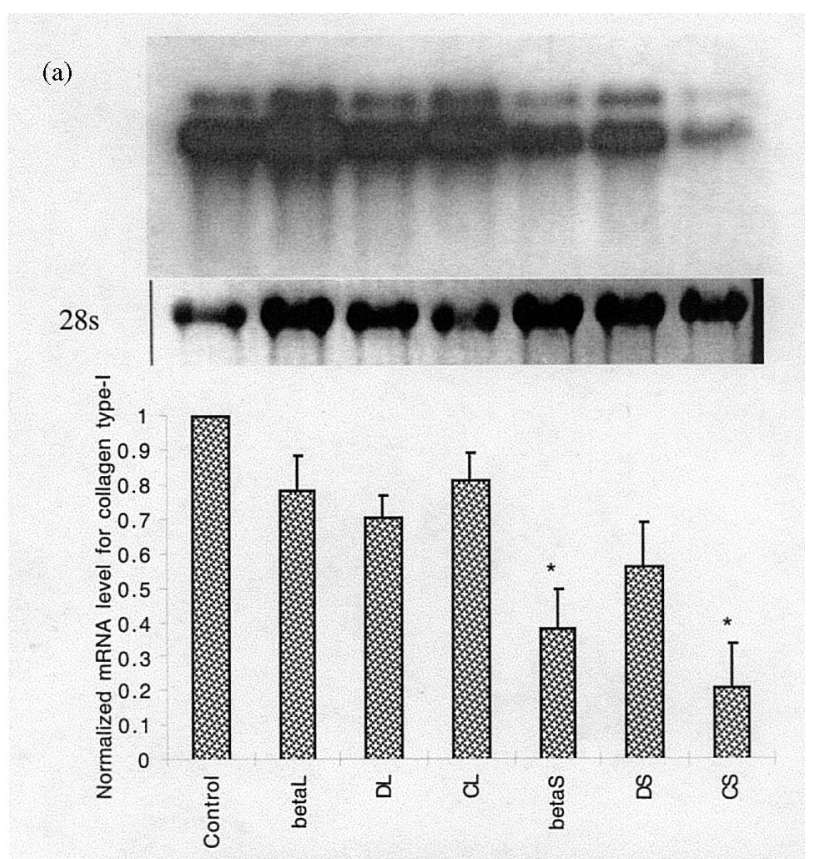

(b)

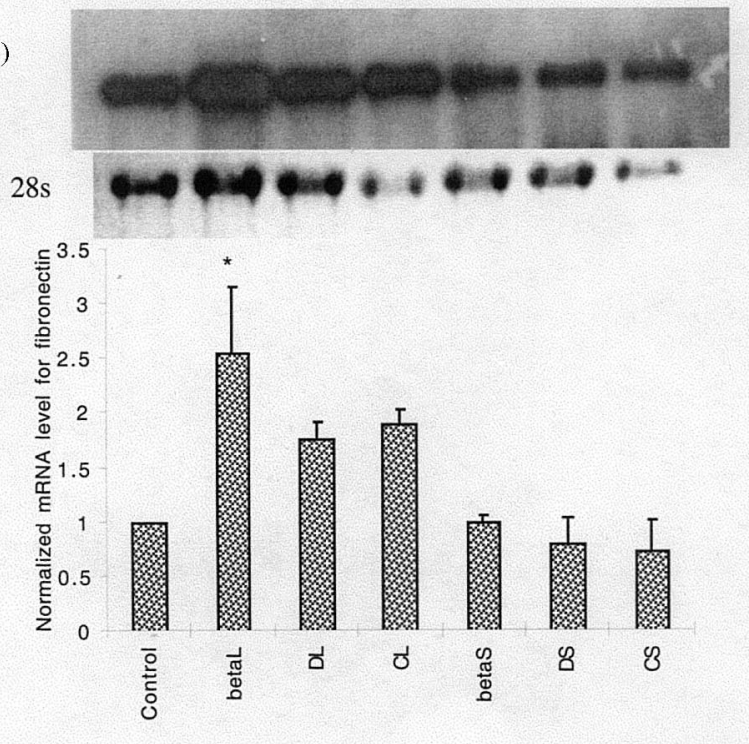

Fig. 6. mRNA expression for (a) type I collagen and (b) fibronectin of osteoblasts in contact with CPC particles for $24 \mathrm{~h}$ (mean value \pm SE, $n=3$ ). A decrease of mRNA level for type I collagen was observed for the particles $\beta_{\mathrm{S}}$ and $\mathrm{C}_{\mathrm{S}}$, while an increase of mRNA level for fibronectin was found for the particles $\beta_{\mathrm{L}}$ (*: statistical differences with respect to control, $n=3$ and $P<0.02$ ).

also be due to a decrease of osteoblast adhesion. Indeed, the osteoblast is an anchorage-dependent cell. If its adhesion process is perturbed, the osteoblast functions could be affected. This hypothesis was based on our recent finding that $\mathrm{Ti}$ particles affected osteoblasts adhesion [29]. From the intracellular events, CPC particles could modify the signal pathway with a possible consequence of decreasing the osteoblast functions as it was demonstrated for Ti particles [30].

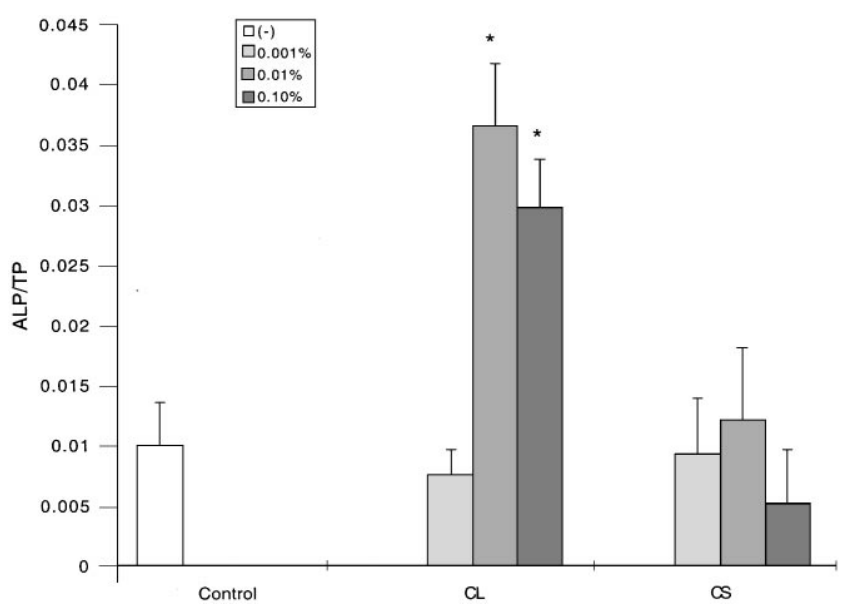

Fig. 7. Quantification of ALP production normalized by the total protein production of osteoblasts co-cultured with CPC particles $\mathrm{C}_{\mathrm{L}}$ and $\mathrm{C}_{\mathrm{S}}$ at three concentrations for $48 \mathrm{~h}$ (mean value $\pm \mathrm{SE}$ ). An increase in ALP production was found for the particles $C_{L}$ at concentrations 0.01 and $0.1 \%$ and for the particles $C_{S}$ at concentrations $0.01 \%$ (*: statistical differences with respect to control, $n=9$ and $P<0.02$ ).

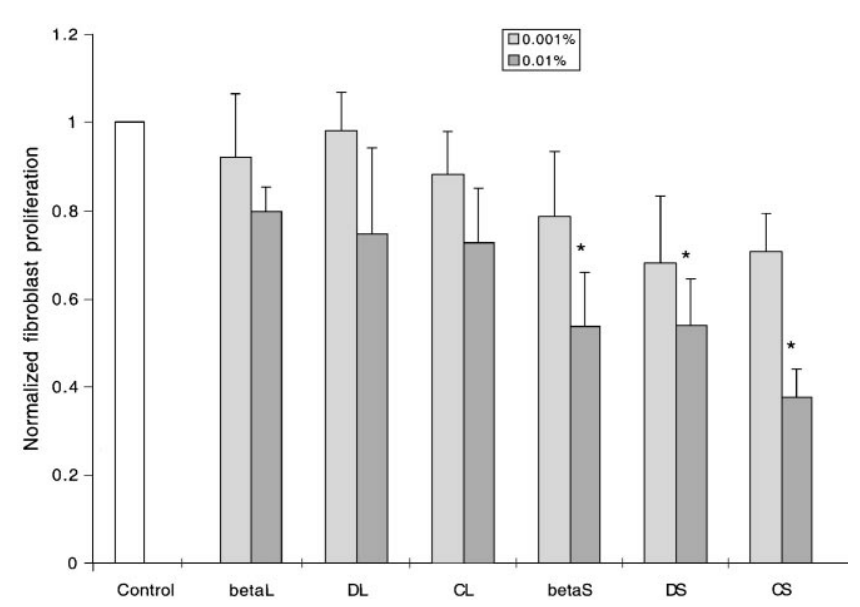

Fig. 8. Dose, size and material effects of the CPC particles on fibroblasts proliferation after $72 \mathrm{~h}$ (mean value $\pm \mathrm{SE}$ ). The fibroblasts proliferation was inhibited by the small particles $\left(\beta_{\mathrm{S}}, \mathrm{D}_{\mathrm{S}}, \mathrm{C}_{\mathrm{S}}\right)$ and a dose effect was observed $(*$ : statistical differences with respect to control, $n=9$ and $P<0.01)$.

The CPC particles used in this study were shown to modulate the gene expression of the osteoblasts. This kind of results has already been noted for type I collagen when osteoblast-like cells were in contact with titanium particles $[29,31]$. Decrease of extracellular matrix production could lead to a slower CPC osteointegration. Modulation of genes expression could be caused by a reorganization of actin filament as shown in a study using Ti particles [29]. In fact, the change in actin filament organization could influence the nuclear matrix architecture and modulate the expression of different genes as demonstrated recently $[32,33]$. 
The decrease of osteoblast functions in contact with CPC used in bulk form has been documented and was attributed to the acidification of the medium due to the dissolution of the CPC [11]. This in vitro finding could partially explain the fact that osteoblasts were not or very rarely found at the cement surface during an in vivo study performed on rabbits [14]. In the present study, the acidification of the medium could not be responsible for the decrease of osteoblast functions as we verified that the $\mathrm{pH}$ value of the medium did not change for each CPC particle concentration used. It was then the direct interaction of osteoblasts with particles which was involved in the decrease of osteoblast functions.

CPC particles had no indirect effect on osteoblasts viability. This result is in opposition to a previous study using Ti particles [17]. The number and the size distribution of particles for both studies were similar. It seems then that the chemical composition of the particles played an important role for the conditioned medium assay. Depending on the particles composition, an autocrine regulation of osteoblasts could be induced.

The proliferation of fibroblasts was inhibited by CPC particles, even at very low concentrations. In a study using Ti particles, it has been shown that low concentrations of particles could enhance fibroblasts proliferation [34]. The particles were then considered as a possible factor for the creation of the fibrous tissue surrounding the orthopedic implants. Fibroblasts in contact with CPC particles behaved differently. This could explain the absence of fibrous tissue between the cement and the bone observed during an in vivo study [1]. Nevertheless, it has been shown that CPC particles could stimulate the production of potent osteolytic cytokine by fibroblasts [35].

TNF- $\alpha$, which could be produced by macrophages contacted by particles [36] and IL-6, which could be produced by osteoblasts [37] have been shown to be present in the surrounding of prosthesis. It was important to verify that the results of osteoblasts viability were not influenced by these inflammatory cytokines. It should be noted that results on viability alone did not allow to conclude that presence of these cytokines did not influence the osteoblast functions. Indeed, it would be of interest to measure the production of different osteolytic cytokines (like prostaglandin $\mathrm{E}_{2}$ ) when particles and inflammatory cytokines are simultaneously present. This quantification will be performed in a future study.

Recently, some concerns have been raised about the fact that orthopedic particles used during in vitro experiments can be contaminated by endotoxin [38]. It has also been shown that actual treatment for orthopedic implants does not remove the endotoxin [39]. The sterilization procedure used in this study was not designated to specifically remove the endotoxin from the particles, but was identical as for a clinical situation. Endotoxin could have been removed by successively treating the particles in nitric acid and ethanolic sodium hydroxide [35].

To verify that the loading procedure of the particles did not induce by itself a reaction of the osteoblasts, the particles solution was loaded in two steps in another experiment. First, normal medium representing half of the final volume was added. Then, the particle solution representing the second half of the final volume was added. This loading procedure minimized the possible mechanical damages that the particles could induce to the cells. When we compared the viability between the two loading procedures, no difference was noted. The effects of CPC particles on osteoblast functions could not then be the result of the loading procedure.

The present study was performed on rat calvarial osteoblasts. This cell line is well characterized and expresses the normal phenotypic features of osteoblast [18]. Nevertheless, extension of the present results to human osteoblast should be done with caution. Even with human osteoblast-like cells, interaction with particles could furnish different cytotoxic results between different cell lines [28]. Results of this in vitro study should then be considered as an indication of possible negative osteoblast reactions to particles that can be found in patients treated with CPC.

Although it has been noted that small particles were present during the process of CPC resorption $[1,13,14]$, no quantitative information on the particle number was reported. Direct correlations between in vivo and in vitro studies were then difficult to perform. To obtain some critical values, the CPC particle concentrations used in this study covered three orders of magnitude. The lowest concentration $(0.001 \%)$ for the particles $\mathrm{C}_{\mathrm{S}}$ corresponded to approximately 5 particles per osteoblast. This concentration could be considered as a low clinical situation for particles concentration when compared to the particles generated from orthopedic implants [40]. Histological studies are needed to determine the amount of particles that are present after implantation of CPC.

\section{Conclusions}

The results of this study clearly established that CPC particles could be harmful for the osteoblasts, especially when their size was smaller than $10 \mu \mathrm{m}$. A decrease of viability, proliferation and production of extracellular matrix was measured. A dose effect was present, ratio of 50 CPC particles per osteoblast could be considered as the maximum of what an osteoblast supported. The rational for using CPC is that this material will be completely resorbed and replaced by new bone. Two processes are simultaneously involved: (i) the degradation of CPC performed by osteoclasts and macrophages, and (ii) the creation of new bone performed by osteoblasts. Pres- 
ence of CPC particles could disturb the osteoblasts ability to make new bone. An unstable mechanical situation could result if the bone formation is delayed by the particles compared to the CPC degradation. It would then be important for future CPC development to minimize the generation of particles smaller than $10 \mu \mathrm{m}$.

\section{Acknowledgements}

The authors thank John Kim and Adam Hsieh for their technical assistance. This work was supported by the Swiss Foundation of Medicine and Biology Grants, by NIH grant \#AR14918, and OREF Bristol-Meyers grant \# 59212A.

\section{References}

[1] Frankenburg EP, Goldstein SA, Bauer TW, Harris SA, Poser RD. Biomechanical and histological evaluation of a calcium phosphate cement. J Bone Jt Surg 1998;80A:1112-24.

[2] Ohura K, Bohner M, Hardouin P, Lemaître J, Pasquier G, Flautre B. Resorption of, and bone formation from, new $\beta$-tricalcium phosphate-monocalcium phosphate cements: an in vivo study. J Biomed Mater Res 1996;30:193-200.

[3] Yamamoto H, Niwa S, Hori M, Hattori T, Sawai K, Aoki S, Hirano M, Takeuchi H. Mechanical strength of calcium phosphate cement in vivo and in vitro. Biomaterials 1998; 19:1587-91.

[4] Chow LC, Markovic M, Tagaki S. Calcium phosphate cements. In: Struble LJ, editor. Cements research progress. Westerville, OH: The American Ceramic Society, 1998. p. 215-37.

[5] Mirtchi AA, Lemaître J, Munting E. Calcium phosphate cements: action of setting regulators on the properties of the $\beta$-tricalcium phosphate-monocalcium phosphate cements. Biomaterials 1989;10:634-8.

[6] Van Landuyt P, Lowe C, Lemaître J. Optimization of setting time and mechanical strength of $\beta$-TCP/MCPM cements. Bioceramics 1997; 10:477-80.

[7] Van Landuyt P, Pouchkine G, Lemaître J. Influence of polysaccharides on brushite cement properties. Bioceramics 1998;11:255-8.

[8] Moore DC, Frankenburg EP, Goulet JA, Goldstein SA. Hip screw augmentation with an in situ-setting calcium phosphate cement: an in vitro biomechanical analysis. J Orthop Trauma 1997;11:577-83.

[9] Bohner M, Lemaître J, Van Landuyt P, Zambelli P-Y, Merkle HP, Gander B. Gentamicin-loaded hydraulic calcium phosphate bone cement as antibiotic delivery system. J Pharm Sci 1997;86:565-72.

[10] Higashi S, Ohsumi T, Ozumi K, Kuroki K, Inokuchi Y, Terashita M. Evaluation of cytotoxicity of calcium phosphate cement consisting of $\alpha$-tricalcium phosphate and dicalcium phosphate dihydrate. Dent Mater J 1998;17:186-94.

[11] Oreffo RO, Driessens FC, Planell JA, Triffitt JT. Growth and differentiation of human bone marrow osteoprogenitors on novel calcium phosphate cements. Biomaterials 1998;19:1845-54.

[12] Yoshimine Y, Sumi M, Isobe R, Anan H, Maeda K. In vitro interaction between tetracalcium phosphate-based cement and calvarial osteogenic cells. Biomaterials 1996;17:2241-5.

[13] Constantz BR, Barr BM, Ison IC, Fulmer MT, Baker J, McKinney L, Goodman SB, Gunasekaren S, Delaney DC, Ross J, Poser
RD. Histological, chemical, and crystallographic analysis of four calcium phosphate cements in different rabbit osseous sites. J Biomed Mater Res 1998;43:451-61.

[14] Frayssinet P, Gineste L, Conte P, Fages J, Rouquet N. Short-term implantation effects of a DCPD-based calcium phosphate cement. Biomaterials 1998;19:971-7.

[15] Glant TT, Jacobs JJ. Response of three murine macrophage populations to particulate debris: bone resorption in organ cultures. J Orthop Res 1994;12:720-31.

[16] Shanbhag AS, Macaulay W, Stefanovic-Racic M, Rubash HE. Nitric oxide release by macrophages in response to particulate wear debris. J Biomed Mater Res 1998;5:497-503.

[17] Pioletti DP, Takei H, Kwon SY, Wood D, Sung K-LP. The cytotoxic effect of titanium particles phagocytosed by osteoblasts. J Biomed Mater Res 1999;46:399-407.

[18] Puleo DA, Holleran LA, Domerus RH, Bizios R. Osteoblast response to orthopaedic implants in vitro. J Biomed Mater Res 1991;25:711-23.

[19] Koerten HK, Van der Meulen J. Degradation of calcium phosphate ceramics. J Biomed Mater Res 1999;44:78-86.

[20] Alliot-Licht B, Gregoire M, Orly I, Menanteau J. Cellular activity of osteoblasts in the presence of hydroxyapatite: an in vitro experiment. Biomaterials 1991;12:752-6.

[21] Sun J-S, Tsuang Y-H, Liao C-J, Liu H-C, Hang Y-S, Lin F-H. The effects of calcium phosphate particles on the growth of osteoblasts. J Biomed Mater Res 1997;37:324-34.

[22] Andrew SM, Andrew JG, Hayland JA, Wroblewski BM, Freemont AJ. Interleukin-6 in membrane from late loosening of hip arthroplasties. Trans Orthop Res Soc 1993:243.

[23] Goodman SB, Huie P, Song Y, Lee K, Doshi A, Rushdieh B, Woolson S, Maloney W, Schurman D, Sibley R. Loosening and osteolysis of cemented joint arthroplasties. Clin Orthop Rel Res 1997;337:149-63.

[24] Van Landuyt P, Lemaitre J. Synthesis of $\beta$-tricalcium phosphate powder with controlled specific surface area. Bioceramics 1996;9:205-8.

[25] Stringa E, Filanti C, Giunciuglio D, Albini A, Manduca P. Osteoblastic cells from rat long bone. Characterization of their differentiation in culture. Bone 1996;16:663-70.

[26] Einhorn TA. The bone organ system: form and function. In: Marcus R, Feldman D, Kelsey J, editors. Osteoporosis. San Diego: Academic press, 1996. p. 3-22.

[27] Jones KH, Senft JA. An improved method to determine cell viability by simultaneous staining with fluorescein diacetatepropidium iodide. J Histochem Cytochem 1985;33:77-9.

[28] Allen MJ, Myer BJ, Millett PJ, Rushton N. The effects of particulate cobalt, chromium and cobalt-chromium alloy on human osteoblast-like cells in vitro. J Bone Jt Surg 1997; 79B:475-82.

[29] Kwon SY, Takei H, Pioletti DP, Lin T, Ma QJ, Akeson, WH, Wood DJ, Sung KLP. Titanium particles inhibit osteoblast adhesion to fibronectin-coated substrates. J Orthop Res 2000, to appear.

[30] Takei H, Pioletti DP, Kwon SY, Sung KLP. Inhibition of osteoblast proliferation by titanium particles: involvement of intracellular events. J Orthop Res 2000, under revision.

[31] Yao J, Cs-Szabo G, Jacobs JJ, Kuettner KE, Glant TT. Suppression of osteoblast function by titanium particles. J Bone Jt Surg 1997;79A:107-12.

[32] Bidwell JP, Alvarez M, Feister H, Onyia J, Hock J. Nuclear matrix proteins and osteoblast gene expression. J Bone Miner Res 1998;13:155-67.

[33] Chen CS, Mrksich M, Huang S, Whitesides GM, Ingber DE. Geometric control of cell life and death. Science 1997;276:1425-8.

[34] Maloney WJ, Smith RL, Castro F, Schurman DJ. Fibroblast response to metallic debris in vitro. J Bone Jt Surg 1993; 75A:835-44. 
[35] Ninomiya JT, Honari D, Struve JA, Stelloh CS, Toth JM, Young DA. Effects of hydroxyapaptite particulate debris on the expression and secretion of cytokines and proteolytic enzymes in human fibroblasts. Proceedings of the 45th ORS, 1999. p. 26.

[36] Glant TT, Jacobs JJ, Molna'r G, Shanbhag AS, Valyon M, Galante JO. Bone-resorption activity of particulate-stimulated macrophages. J Bone Miner Res 1993;8:1071-9.

[37] Haynes DR, Rogers SD, Hay S, Pearcy MJ, Howie DW. The differences in toxicity and release of bone-resorbing mediators induced by titanium and cobalt-chromium-alloy wear particles. J Bone Jt Surg 1993;75A:825-34.
[38] Cho DR, Hong CY, Baran GR, Goldring SR. Adsorbed endotoxin mediates differential effects on particle-induced stmulation of cytokine and chemokine release. Proceedings of the 45th ORS, 1999. p. 6.

[39] Van de Motter RR, Goldberg VM, Ninomiya JT, Greefield EM. Adherent endotoxin exists on orthopaedic implant surfaces and wear particles. Proceedings of the 45th ORS, 1999. p. 873.

[40] Brien WW, Salvati EA, Betts F, Bullough P, Wright T, Rimnac C, Bully R, Garvin K. Metal levels in cemented total hip arthroplasty. Clin Orthop 1992;276:66-74. 